\title{
Tripterygium glycosides inhibit inflammatory mediators in the rat synovial RSC-364 cell line stimulated with interleukin-1 $\beta$
}

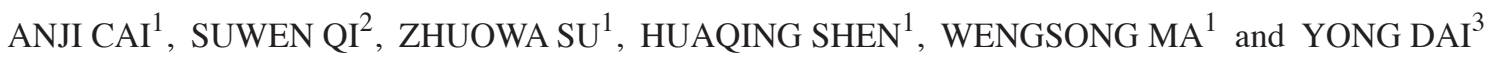 \\ ${ }^{1}$ Department of Clinical Laboratory, Nanshan Affiliated Hospital of Guangdong Medical College; \\ ${ }^{2}$ Department of Biomedical Engineering, Medical School, Shenzhen University; ${ }^{3}$ The Second Clinical Medical College, \\ Jinan University, Shenzhen People's Hospital, Shenzhen, Guangdong 518020, P.R. China
}

Received October 15, 2014; Accepted April 24, 2015

DOI: $10.3892 /$ br.2015.501

\begin{abstract}
Tripterygium glycosides (TG) are extracted from a traditional Chinese medicinal herb. Using the compound, progress has been made in the treatment of rheumatoid arthritis (RA), but the underlying mechanism of its action is poorly understood. The purpose of the present study was to investigate the role of TG in preventing inflammatory arthritis. An inflammatory cell model was established in the rat synovial RSC-364 cell line via induction with interleukin (IL)-1 $\beta$. The expression of IL-32 and matrix metalloproteinases (MMP-1 and MMP-9) was determined using an enzyme-linked immunosorbent assay. Compared with the control group (without IL-1 $\beta$ ), IL-1 $\beta$ in the treatment group induced the expression of IL-32, MMP-1 and MMP-9 in RSC-364 cells. When a different dose of TG was added to RSC-364 cells stimulated with IL-1 $\beta$, TG decreased the expression levels of IL-32, MMP-1 and MMP-9 in a dose-dependent manner. These results indicated that TG suppressed the inflammation response in RSC-364 cells. Taken together, these findings may contribute to a better understanding of the role of TG in the anti-inflammatory therapeutics for RA.
\end{abstract}

\section{Introduction}

Rheumatoid arthritis (RA) is a chronic inflammatory disorder that affects multiple peripheral joints (1). RA is the most common form of inflammatory arthritis and is characterized by synovial hyperplasia, which results in the evolution of joint destruction $(2,3)$. Tripterygium glycosides (TG) are a traditional Chinese medicinal herb with which progress has been

Correspondence to: Professor Yong Dai, The Second Clinical Medical College, Jinan University, Shenzhen People's Hospital, 1017 Dongmen North Road, Shenzhen, Guangdong 518020, P.R. China

E-mail: daiyong22@aliyun.com

Key words: Tripterygium glycosides, interleukin-1 $\beta$, RSC-364, inflammation mediator made in the treatment of RA, but the underlying mechanism of its action is poorly understood.

Interleukin (IL)-32 is a relatively recently described pro-inflammatory cytokine reported to have a role in RA (4). IL-32 is produced mainly by T cells, natural killer cells, epithelial cells and monocytes. Notably, IL-32 is highly expressed in fibroblast-like synoviocytes (FLS) from RA patients and has been recently identified as a possible RA prognostic biomarker (5-7).

Matrix metalloproteinases (MMPs) are key enzymes in the degradation of extracellular matrices and MMP expression plays important roles in inflammatory diseases (8). Inflammatory cytokines, such as IL-1 $\beta$ and tumor necrosis factor- $\alpha$, stimulate the production of MMPs, and enzymes, including MMP-1 and MMP-9, can degrade the components of the extracellular matrix in RA FLS (9).

Earlier studies reported that the key pro-inflammatory cytokines, such as IL-1 $\beta$, are present in the synovial fluid of RA patients and play key roles in amplifying and perpetuating inflammation and joint destruction (10). In addition, IL-1 $\beta$ is also a potent activator of FLS, inducing them to produce cytokines, matrix-degrading metalloproteinases and other inflammatory mediators (11).

RA treatment has received increasing attention. TG is an extract derived from Tripterygium wilfordii Hook $\mathrm{F}$ and has been widely used in the treatment of RA, autoimmune disease and inflammatory disease in China (12). TG can evidently improve the symptoms and laboratory indicators of RA (13). Although the clinical efficacy of TG has been verified, its basic mechanism of action remains unclear. In the present study, to gain insight into the potential mechanisms underlying the therapeutic value of TG for RA, RSC-364 cells treated with IL-1 $\beta$ were employed to establish an inflammation study model in vitro. The observations indicated that TG reduced the expression levels of IL-32, MMP-1 and MMP-9.

\section{Materials and methods}

Cell culture. A rat synovial cell line, RSC-364 (donated by Beijing 301 Hospital, Beijing, China), was cultured in Dulbecco's modified Eagle's medium (DMEM; Gibco, Invitrogen Life Technologies, Carlsbad, CA, USA) supplemented with $10 \%$ fetal bovine serum (FBS; Sigma-Aldrich, 
St. Louis, MO, USA), $100 \mathrm{U} / \mathrm{ml}$ penicillin and $100 \mathrm{U} / \mathrm{ml}$ streptomycin at $37^{\circ} \mathrm{C}$ in a humidified atmosphere of $5 \% \mathrm{CO}_{2}$ and 95\% air. The RSC-364 cells were grown to $70 \%$ confluence in 6-well plates $\left(\sim 5 \times 10^{5}\right.$ cells) for testing. The enzyme-linked immunosorbent assay (ELISA) kits of IL-32, MMP-1 and MMP-9 were from R\&D Systems (Minneapolis, MN, USA).

ELISA assay. RSC-364 cells were seeded in 6-well plates and cultured in DMEM with 10\% FBS for $24 \mathrm{~h}$ before treatment. RSC-364 cells of the IL-1 $\beta$ groups were treated with IL-1 $\beta$ $(10 \mathrm{ng} / \mathrm{ml})$ for $3 \mathrm{~h}$, and the control group cells had no treatment. Cell culture supernatants were then collected. To further study the effect of TG on IL-32, MMP-1 and MMP-9 expression in RSC-364 cells treated with IL-1 $\beta$, the cells were pre-treated with IL-1 $\beta$ for $3 \mathrm{~h}$, and subsequently, different doses $(5,10$, 20 and $40 \mathrm{mg} / \mathrm{dl}$ ) of TG (dissolved in anhydrous alcohol) were added to each well. After $24 \mathrm{~h}$, the supernatants were collected for detection of the expression levels of IL-32, MMP-1 and MMP-9 using ELISA. ELISA was performed according to the manufacturer's instructions. All the experiments were performed in triplicate. Employing commercially available kits, the expression values were calculated on the basis of the standard curve constructed for each assay.

Statistical analysis. All the data were entered into a computer database and analyzed using SPSS 13.0 software (SPSS, Inc., Chicago, IL, USA). The results were expressed as the mean \pm standard deviation and statistical comparisons were performed using a completely randomized design analysis of variance and least significant difference. In all the cases, $\mathrm{P}<0.05$ was considered to indicate a statistically significant difference.

\section{Results}

$I L-1 \beta$ induces the expression of $I L-32, M M P-1$ and MMP-9 in RSC-364 cells. The group that did not receive IL-1 $\beta$ was used as a control group. In the treatment groups, IL-32, MMP-1 and MMP-9 levels were significantly increased $(\mathrm{P}<0.01)$ compared with the control group (Fig. 1). These findings showed that IL-1 $\beta$ induced the expression of IL-32, MMP-1 and MMP-9 in RSC-364 cells. These results also verified that the in vitro inflammatory cell model was successful.

$T G$ inhibits the expression of $I L-32, M M P-1$ and MMP-9 in RSC-364 cells treated with $I L-1 \beta$. As shown in Figs. 2-4, at 5 dose points, there was a significant difference in the expression of IL-32, MMP-1 and MMP-9 at the $10(\mathrm{P}<0.05)$, $20(\mathrm{P}<0.01)$ and $40 \mathrm{mg} / \mathrm{dl}$ dose $(\mathrm{P}<0.01)$ compared to that of the $0 \mathrm{mg} / \mathrm{dl}$ dose. The results showed that $5 \mathrm{mg} / \mathrm{dl}$ of TG decreased the expression of IL-32, MMP-1 and MMP-9 following stimulation with IL-1 $\beta$ in RSC-364 cells, but the difference was not clear when compared to that at the $0 \mathrm{mg} / \mathrm{dl}$ dose (without TG treatment). A decreased expression of IL-32, MMP-1 and MMP-9 was detected at the $10 \mathrm{mg} / \mathrm{dl}$ dose and reached its original levels at $40 \mathrm{mg} / \mathrm{dl}$ dose following TG treatment in RSC-364 induced with IL-1 $1 \beta$. These findings indicated that TG downregulated the expression levels of IL-32, MMP-1 and MMP-9 in RSC-364 cells stimulated with IL-1 $\beta$.

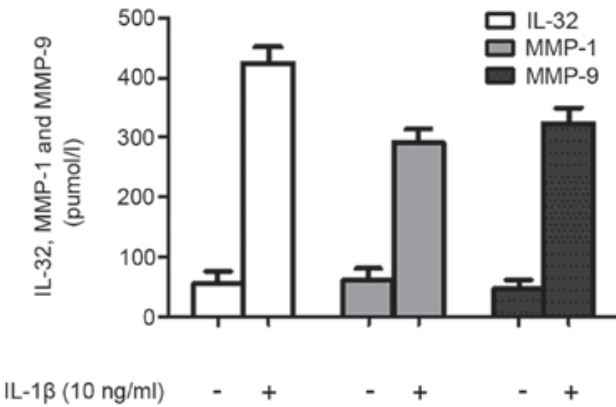

Figure 1. IL-1 $\beta$ induces the production of IL-32, MMP-1 and MMP-9 in RSC-364 cells. IL, interleukin; MMP, matrix metalloproteinase.

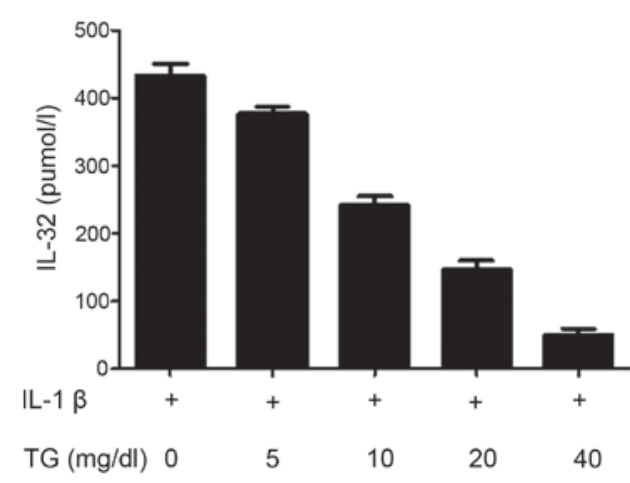

Figure 2. Effects of TG on the expression of IL-32 in RSC-364 cells stimulated with IL-1 $\beta$. TG, Tripterygium glycosides; IL, interleukin; MMP, matrix metalloproteinase.

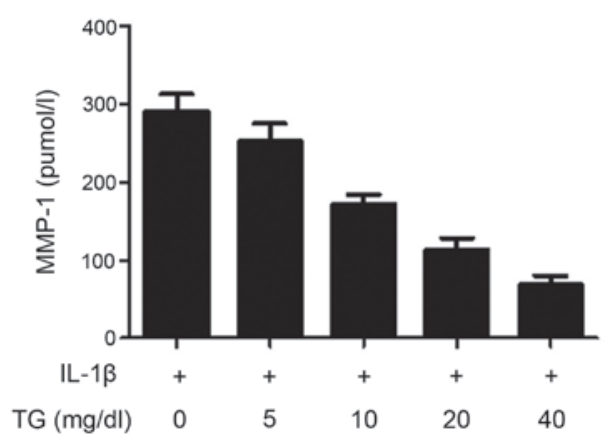

Figure 3. Effects of TG on the expression of MMP-1 in RSC-364 cells stimulated with IL-1 $\beta$. TG, Tripterygium glycosides; IL, interleukin; MMP, matrix metalloproteinase.

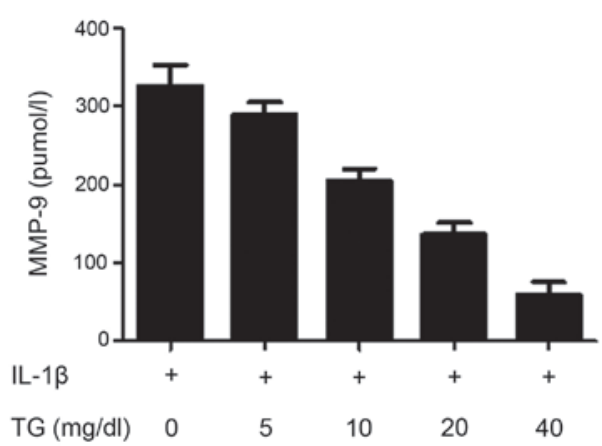

Figure 4. Effects of TG on the expression of MMP-9 in RSC-364 cells stimulated with IL-1 $\beta$. TG, Tripterygium glycosides; IL, interleukin; MMP, matrix metalloproteinase. 


\section{Discussion}

RA is a chronic inflammatory disease characterized by inflammation of the synovial lining and destruction of the adjacent bone and cartilage (14). It is well-known that TG is an effective RA treatment $(15,16)$. However, extremely little is known regarding the detailed mechanism underlying the effects of TG in RA. IL-1 $\beta$ is known to induce the production of a variety of cytokines in fibroblasts. It has been reported that IL-32, MMP-1 and MMP-9 are considered to play critical roles in the pathogenesis of RA (17-19).

In the present study, whether IL-1 $\beta$ induced the production of IL-32, MMP-1 and MMP-9 in RSC-364 cells was explored. The results showed that IL-1 $\beta$ clearly increased the expression levels of L-32, MMP-1 and MMP-9 compared with that of the control group (without IL-1 $\beta$ treatment) in RSC-364 cells. This is consistent with a study by Kim et al (20), which noted that IL-32 has the properties of pro-inflammatory mediators via stimulation of IL-1 $\beta$ and is found in large quantities in the synovial fibroblasts of RA patients. Of note, it also suggested that the inflammatory cell model in vitro was extremely successful.

TG has anti-inflammatory and immunosuppressive activities in human clinical trials for inflammatory and autoimmune disease and has been historically used in traditional Chinese medicine to treat RA (21). Recently, IL-32 has been identified with a high expression in RA patients and mice models of experimental inflammatory arthritis (22). Furthermore, IL-32 is a pro-inflammatory cytokine expressed by activated natural killer cells, T cells and fibroblasts (23). In vitro studies confirm that TG strongly inhibits proliferation of T and B cells, and has demonstrated immunosuppressive activity (24). The present findings showed that TG could hamper the expression levels of IL-32 in a dose-dependent manner in RSC-364 cells stimulated with IL-1 $\beta$. Therefore, we assumed that TG decreased the expression levels of IL-32 in RSC-364 cells stimulated with IL-1 $\beta$, which may be associated with the suppression of the fibroblasts cells activity.

MMPs are involved in the articular tissue destruction processes in the pathogenesis of RA and have been shown to dissolve the extracellular matrix, initiating and promoting new vessel formation in RA. A recent study of the effects of TG extracts on inflammatory enzymes, such as metalloproteinases, showed an inhibition of metalloproteinase production by blocking mRNA transcription (25). In addition, several studies show that TG also decreases the production of MMPs by suppressing the proliferation of $\mathrm{T}$ and $\mathrm{B}$ cells and synovial fibroblasts in RA $(26,27)$. In the present study, the results identified that TG clearly decreased the production of MMP-1 and MMP-9 in a dose-dependent manner in RSC-364 cells stimulated with IL-1 $\beta$. Earlier clinical studies suggest that the anti-inflammatory effects of TG in the treatment of RA are due to the suppression of the MMPs (28). Consequently, we thought that TG could suppress the expression of MMP-1 and MMP-9 by inhibiting the proliferation of cells and blocking $M M P-1$ and MMP-9 mRNA transcription in RSC-364 cells stimulated with IL-1 $\beta$.

In conclusion, the present study suggested that TG suppressed the expression of IL-32, MMP-1 and MMP-9 in a dose-dependent manner. These results contribute to further explanation of the mechanism of TG in the treatment of RA.
TG may be an attractive agent for the development of potential RA therapeutic agents. However, the present study was an in vitro experiment and thus, reliable in vivo conclusions cannot be drawn from these results. Therefore, further investigations are required to confirm the results of the study.

\section{Acknowledgements}

Dr Anji Cai would like to thank his family for their encouragement and the central laboratory of the Nanshan Affiliated Hospital of Guangdong Medical College for providing the space where this work was conducted.

\section{References}

1. Firestein GS: Evolving concepts of rheumatoid arthritis. Nature 423: 356-361, 2003

2. Bartok B and Firestein GS: Fibroblast-like synoviocytes: Key effector cells in rheumatoid arthritis. Immunol Rev 233: 233-255, 2010.

3. Izquierdo E, Cañete JD, Celis R, Del Rey MJ, Usategui A, Marsal S, Sanmartí R, Criado G and Pablos JL: Synovial fibroblast hyperplasia in rheumatoid arthritis: Clinicopathologic correlations and partial reversal by anti-tumor necrosis factor therapy. Arthritis Rheum 63: 2575-2583, 2011.

4. Kim SH, Han SY, Azam T, Yoon DY and Dinarello CA: Interleukin-32: A cytokine and inducer of TNFalpha. Immunity 22: 131-142, 2005

5. Joosten LA, Netea MG, Kim SH, Yoon DY, Oppers-Walgreen B, Radstake TR, Barrera P, van de Loo FA, Dinarello CA and van den Berg WB: IL-32, a proinflammatory cytokine in rheumatoid arthritis. Proc Natl Acad Sci USA 103: 3298-3303, 2006.

6. Alsaleh G, Sparsa L, Chatelus E, Ehlinger M, Gottenberg JE, Wachsmann D and Sibilia J: Innate immunity triggers IL-32 expression by fibroblast-like synoviocytes in rheumatoid arthritis. Arthritis Res Ther 12: R135, 2010.

7. Heinhuis B, Koenders MI, van Riel PL, van de Loo FA, Dinarello CA, Netea MG, van den Berg WB and Joosten LA: Tumour necrosis factor alpha-driven IL-32 expression in rheumatoid arthritis synovial tissue amplifies an inflammatory cascade. Ann Rheum Dis 70: 660-667, 2011.

8. Burrage PS, Mix KS and Brinckerhoff CE: Matrix metalloproteinases: Role in arthritis. Front Biosci 11: 529-543, 2006.

9. Feldmann $M$ and Maini RN: The role of cytokines in the pathogenesis of rheumatoid arthritis. Rheumatology (Oxford) 38 (Suppl 2): 3-7, 1999.

10. Abramson SB and Yazici Y: Biologics in development for rheumatoid arthritis: relevance to osteoarthritis. Adv Drug Deliv Rev 58: 212-225, 2006.

11. Jeong JG, Kim JM, Cho H, Hahn W, Yu SS and Kim S: Effects of IL-1beta on gene expression in human rheumatoid synovial fibroblasts. Biochem Biophys Res Commun 324: 3-7, 2004.

12. Tao X, Cush JJ, Garret M and Lipsky PE: A phase I study of ethyl acetate extract of the chinese antirheumatic herb Tripterygium wilfordii hook $\mathrm{F}$ in rheumatoid arthritis. J Rheumatol 28 : 2160-2167, 2001.

13. Qiu D and Kao PN: Immunosuppressive and anti-inflammatory mechanisms of triptolide, the principal active diterpenoid from the Chinese medicinal herb Tripterygium wilfordii Hook. f. Drugs R D 4: 1-18, 2003.

14. Shibuya H, Yoshitomi H, Murata K, et al: TNF $\alpha, P D G F$ and TGF $\beta$ synergistically induce synovial lining hyperplasia via inducible PI3Kס. Mod Rheumatol 25: 72-78, 2015.

15. Li J, Lu Y, Xiao C, Lu C, Niu X, He X, Zhao H, Tan Y and $\mathrm{Lu} \mathrm{A}$ : Comparison of toxic reaction of Tripterygium wilfordii multiglycoside in normal and adjuvant arthritic rats. J Ethnopharmacol 135: 270-277, 2011.

16. Tao X, Younger J, Fan FZ, Wang B and Lipsky PE: Benefit of an extract of Tripterygium Wilfordii Hook F in patients with rheumatoid arthritis: A double-blind, placebo-controlled study. Arthritis Rheum 46: 1735-1743, 2002.

17. Lequerré T, Jouen F, Brazier M, Clayssens S, Klemmer N, Ménard JF, Mejjad O, Daragon A, Tron F, Le Loët X, et al: Autoantibodies, metalloproteinases and bone markers in rheumatoid arthritis patients are unable to predict their responses to infliximab. Rheumatology (Oxford) 46: 446-453, 2007. 
18. Gui M, Zhang H, Zhong K, Li Y, Sun J and Wang L: Clinical significance of interleukin-32 expression in patients with rheumatoid arthritis. Asian Pac J Allergy Immunol 31: 73-78, 2013.

19. Scherer S, de Souza TB, de Paoli J, Brenol CV, Xavier RM, Brenol JC, Chies JA and Simon D: Matrix metalloproteinase gene polymorphisms in patients with rheumatoid arthritis. Rheumatol Int 30: 369-373, 2010.

20. Kim KS, Choi HM, Oh H, Kim C, Jeong JS, Yoo MC and Yang HI: Effect of taurine chloramine on the production of matrix metalloproteinases (MMPs) in adiponectin - or IL-1beta-stimulated fibroblast-like synoviocytes. J Biomed Sci 17 (Suppl 1): S27, 2010.

21. Lv QW, Zhang W, Shi Q, Zheng WJ, Li X, Chen H, Wu QJ, Jiang WL, Li HB, Gong L, et al: Comparison of Tripterygium wilfordii Hook $\mathrm{F}$ with methotrexate in the treatment of active rheumatoid arthritis (TRIFRA): A randomised, controlled clinical trial. Ann Rheum Dis annrheumdis-2013-204807, 2014.

22. Xu WD, Zhang M, Feng CC, Yang XK, Pan HF and Ye DQ IL-32 with potential insights into rheumatoid arthritis. Clin Immunol 147: 89-94, 2013

23. Goda C, Kanaji T, Kanaji S, Tanaka G, Arima K, Ohno S and Izuhara K: Involvement of IL-32 in activation-induced cell death in T cells. Int Immunol 18: 233-240, 2006.
24. Chan MA, Kohlmeier JE, Branden M, Jung M and Benedict SH: Triptolide is more effective in preventing $\mathrm{T}$ cell proliferation and interferon-gamma production than is FK506. Phytother Res 13: 464-467, 1999.

25. Sylvester J, Liacini A, Li WQ, Dehnade F and Zafarullah M Tripterygium wilfordii Hook $\mathrm{F}$ extract suppresses proinflammatory cytokine-induced expression of matrix metalloproteinase genes in articular chondrocytes by inhibiting activating protein-1 and nuclear factor-kappaB activities. Mol Pharmacol 59: 1196-1205, 2001.

26. Bao J and Dai SM: A Chinese herb Tripterygium wilfordi Hook F in the treatment of rheumatoid arthritis: Mechanism, efficacy, and safety. Rheumatol Int 31: 1123-1129, 2011.

27. Tao X, Cush JJ, Garret M and Lipsky PE: A phase I study of ethyl acetate extract of the chinese antirheumatic herb Tripterygium wilfordii hook $\mathrm{F}$ in rheumatoid arthritis. J Rheumatol 28: 21602167,2001

28. Klimiuk PA, Sierakowski S, Domyslawska I and Chwiecko J: Effect of repeated infliximab therapy on serum matrix metalloproteinases and tissue inhibitors of metalloproteinases in patients with rheumatoid arthritis. J Rheumatol 31: 238-242, 2004. 